\title{
OC-002 TREATING OCCULT COELIAC DISEASE WITH A GLUTEN-FREE DIET IS ASSOCIATED WITH A SIGNIFICANT IMPROVEMENT IN QUALITY OF LIFE
}

doi:10.1136/gut.2011.239301.2

N R Lewis, ${ }^{1, *}$ R B Hubbard, ${ }^{1}$ D S Sanders, ${ }^{2}$ R F Logan, ${ }^{1}$ G K Holmes, ${ }^{3} \mathrm{~J} \mathrm{West}^{1}{ }^{1}$ Division of Epidemiology, University of Nottingham, Nottingham, UK; ${ }^{2}$ Division of Gastroenterology and Hepatology, Royal Hallamshire Hospital, Sheffield, UK; ${ }^{3}$ Division of Gastroenterology and Hepatology, Royal Derby Hospitals, Derby, UK

Introduction The majority of coeliacs have few obvious gastrointestinal (GI) symptoms despite the presence of the enteropathy, have atypical symptoms or have physiological derangements such as iron deficiency anaemia or osteoporosis. It is not clear whether these coeliacs have a reduced quality of life or whether quality of life changes following treatment with withdrawal of gluten from the diet. Johnson et al. $(n=14)$ observed silent coeliacs had no different life quality at diagnosis nor following 1 year of treatment in comparison to healthy controls ${ }^{1}$ though Nachman et al. $(n=8)$ observed silent coeliacs had significantly worse off quality of life in comparison to controls at diagnosis. ${ }^{2}$ Our aim was to describe the quality of life at diagnosis of coeliac disease in a large contemporary cohort and observe any change following treatment with a gluten-free diet (GFD).

Methods 151 adults newly diagnosed with coeliac disease between 2007 and 2008 at Nottingham, Sheffield and Derby were studied. Quality of life was assessed with SF36 questionnaire. Paired t tests were used to examine changes in SF36 quality of life scores from diagnosis of coeliac disease and following 12 months treatment with GFD. Incident coeliacs were categorised as having a classic presentation (presenting with weight loss and diarrhoea, $\mathrm{n}=22$ ); presenting with

Table 1 OC-002 Quality of life at diagnosis and following treatment of coeliac disease

\begin{tabular}{lccc}
\hline Quality of life & $\begin{array}{c}\text { At diagnosis of } \\
\text { coeliac disease (SD) }\end{array}$ & $\begin{array}{c}\text { Following } \mathbf{1 2} \text { months } \\
\text { GFD (SD) }\end{array}$ & $\begin{array}{c}\text { Mean difference } \\
\text { (95\% CI) }\end{array}$ \\
\hline Mean SF36 score (SD) & $59.1(19.5)$ & $77.7(16.5)$ & $18.5(15.4$ to 21.6) \\
All coeliacs & $48.5(18.8)$ & $67.1(25.1)$ & $18.7(8.4$ to 28.9) \\
Classic disease & $57.4(18.5)$ & $77.4(14.1)$ & 20.0 (15.9 to 24.1) \\
Gl symptoms & $67.6(18.9)$ & $83.2(14.3)$ & 15.5 (9.9 to 21.2) \\
Occult disease & &
\end{tabular}


GI symptoms ( $\mathrm{n}=85$ ); or having occult disease (no GI symptoms or have physiological derangements such as anaemia in absence of GI symptoms, $n=44$ ).

Results Mean SF36 score at diagnosis of coeliac disease was highest in those presenting with occult disease (65.1 (SD 18.6)) and lowest in those with classic disease (48.7 (SD 19.3)). Following exposure to 12 months GFD, there was a statistically significant improvement in quality of life (table 1). The improvement in SF36 score with a GFD was similar regardless of their presenting symptoms at diagnosis.

Conclusion Following diagnosis and treatment of coeliac disease with a GFD, we observed an improvement in quality of life that was similar regardless of the presenting symptoms and signs recorded at diagnosis and the baseline quality of life. Without a randomised controlled trial, we cannot be sure of the true magnitude of this effect over placebo.

Competing interests None.

Keywords coeliac disease.

\section{REFERENCES}

1. Johnston S, Rodgers C, Watson RGP. Quality of life in screen detected and typical celiac disease and the effect of excluding dietary gluten. Eur J Gastroenterol Hepatol 2004:16;1281-6.

2. Nachman F, Mauriño E, Vázquez H, et al. Quality of life in celiac disease patients: Prospective analysis on the importance of clinical severity at diagnosis and the impact of treatment. Dig Liver Dis 2009;41:15-25. 